\title{
Left Behind: Surviving Suicide Loss by Nandini Murali
}

\author{
Published by Westland. 2021, ISBN: 9789389152586
}

\author{
Aishwariya Jha
}

Published online: 7 July 2021

(C) The Author(s), under exclusive licence to Springer Nature India Private Limited 2021

Like an oyster weaving around that which threatens to harm it, Dr. Nandini Murali sublimated her experience in this book-a testimony of grief and the challenges that came with it. Honoring this authentic experience was a courageous and liberating step.

Nandini Murali is a gender and diversity professional and a certified life coach with a focus on loss and transition. She has nearly three decades of national and international experience in the fields of communications, gender, sexuality, mental health, and reproductive health rights and has worked with people affected by HIV/AIDS, vulnerable populations, sex workers, people with disabilities, and non-binary people. Based on her lived experience as a survivor of suicide loss, she established SPEAK (Suicide Prevention Postvention Education Awareness Knowledge), an initiative motivated to change conversations on suicide and promote mental health. She has also played an integral role in the establishment of SPEAK2us, a mental health helpline. She is a communication consultant, a gender and diversity researcher and a student of Vedanta who enjoys poetry, long walks in the wilderness, and photography.

\footnotetext{
A. Jha $(\square)$

Department of Psychiatry, National Institute of Mental

Health and Neurosciences (NIMHANS),

Bangalore 560029, India

e-mail: aishwariyajha@rocketmail.com
}

A storyteller at heart, she has penned down her profound experience with suicide and loss with candor which made for an insightful, inspiring, and moving read.

There is a table of contents at the beginning of the book arranged chronologically with page numbers followed by a touching foreword. Each chapter begins with a quote that follows the theme of the content and makes the reader introspect. She has thoughtfully divided the book into four parts-each a significant insight into her journey.

In Part One, she walks us through a time of unfathomable pain when words usually escape us. When Nandini returned home from an out-oftown assignment she was met with ominous silence and her beloved's lifeless body. Her mind was flooded with images of his smiling face enjoying puris, his frame waving on the porch, and the linen shirt she had brought for him.

The immediate reaction to the trauma was met with a visceral and physical reaction both ached and remedied by Murali's letter and memories. Her first personal experience with suicide felt like a hike through the unchartered terrains of loss and was met with avalanches of emotions-sadness, guilt, anger, confusion, and yearning. When she contemplated breaking the news, she struggled with immense torment. The grey cloud of judgment loomed above, warning her of the instinctive responses concerning her wifely duties and how she had failed in 
preventing this untimely end. She encountered endless questions like it was a mystery to be solved, and conversations with an overt deficit of empathy smeared with ignorant remarks. It was evident that there was a gaping hole in the understanding of the arcane landscape of depression.

The validation that lacked in society, she found in research. Her inquisitiveness and need to decipher her husband's death led her to learn more about suicide and loss. Love and loss, she found, were two sides of the same coin.

Surrendering to the gift of grief, she made the heartening call to speak the truth and celebrate him for the life that he lived rather than perpetuating the stigma that mired the way he died. With soul-searching honesty, she describes the last rituals of immersing a silver form into the waters of Rameshwaram. At the seashore, she had two options- to feel washed ashore or to feel anchored in this new reality. She was determined to choose the latter.

Part Two brings with it a ray of hope. She describes her experiences with Carla Fine, the author of No Time to Say Goodbye: Surviving the Suicide of a Loved One, which like a lighthouse guided her through the fog of grief. Travel and knowledge gave Nandini a fresh perspective and an impetus to create and inform.

Reflecting on her ordeals, she conceptualized the 4Ss-Stigma, Shame, Secrecy, and Silence that form the bedrock of ignorance around suicide, and the 3Cs-Courage, Compassion, and Connection which motivated her to be the change she wished to see. She curated the grim statistics of suicide in India and around the world. The WHO has designated India as the suicide epicenter of South East Asia. Despite the evidence that it needs to be discussed, it is still poorly understood. With the momentum her research garnered, Nandini established the SPEAK foundation challenging stereotypes, spreading awareness, and sensitizing people on suicide prevention. Owning her story and choosing authenticity created a ripple effect that got more people to absolve their shame and embrace self-worth.

Part Three consists of the compelling perspectives of a diverse group of survivors narrated with palpable empathy and grace. What stood out was how each suicide victim was different from the other. Suicide victims also include those who are left behind, reeling from the pain. Disenfranchised grief such as death by suicide and HIV/AIDS, or the death of a divorced spouse, adopted child, or a member of the LGBT$\mathrm{QIA}+$ need to be addressed and validated.

As a psychiatry trainee, I have understood that grief is like a gaping wound that over time attempts to close, leaving behind a painful reminder of the tragedy that occurred. But now and then, waves of emotions wash over the scab that, still weak, gives way. Its experience and duration is unique to every individual, the time between the surges gradually increasing till the pain is replaced by a sweet remembrance of a person that mattered and is now gone.

The final part of the book is raw with wisdom from her personal and professional experience. She appeals to the survivor, the reporter, the loved one, and the health professional providing pioneering advice for those grieving and healing. An advice that I found pragmatic for my practice is the importance ofl anguage in perpetuating and reinforcing negative stereotypes. Phrases like "committed suicide" and "mentally ill" should be interchanged with "died by suicide" and "person with mental illness", as we try to advance in our efforts to address the larger issues around suicide.

I would recommend this book to anyone who wishes to learn more about suicide and loss and those looking for a lifeboat in troubling waters. Her account may aid in sensitizing the readers to the needs of the victims better, as it has with me. Perhaps its availability in libraries will encourage more readers to challenge the lingering misconceptions around suicide. This piece of literature came out in 2021, during the COVID-19 pandemic and may help guide us through our personal and collective losses.

The book has been very beautifully brought out by Westland Publishers and Thomson Press, India. It spans 200 pages in hard print, its prose lucid and easy to read. The author has thoughtfully inserted pertinent references as footnotes and has provided a comprehensive list at the end in the Bibliography section for further reading. A book that is unique in the Indian context, written with both expertise and heart, retails for ₹350, well worth its price.

My first reading was interspersed with several breaks to reflect, digest, and feel the emotions that she has narrated her experience with. The second time, I was reading along with a client of mine, who is also a survivor of suicide loss whom I had gifted the book to, hoping that it would help her. It did. We found 
ourselves discussing things that she could relate to and I could see myself becoming a more sensitive therapist and her, a more validated survivor.

The reader experiences an array of emotions as they voyage with Nandini through turbulent storms and then to placid waters. We find ourselves rooting for her and others we meet along the way, as they acknowledge their scars.

Like the oyster on the cover of the book, Dr. Nandini Murali has used her grief as a catalyst to create an autobiographical pearl that will continue to touch the lives of many. 